\title{
Vagal Schwannoma and Carotid Body Tumor: Magnetic Resonance Imaging Appearance and Differential Diagnosis
}

Makarand Kulkarni

\section{ABSTRACT}

The vagal schwannoma and carotid body tumor are the most important differential of the masses at the level of carotid bifurcation. We reported classical cases of the two conditions with characteristic displacement pattern and morphology.

Keywords: Carotid body tumor, Magnetic resonance imaging, Vagal schwannoma.

How to cite this article: Kulkarni M. Vagal Schwannoma and Carotid Body Tumor: Magnetic Resonance Imaging Appearance and Differential Diagnosis. Int J Head Neck Surg 2015;6(4):195-196

Source of support: Nil

Conflict of interest: None

\section{CASE REPORTS}

The carotid space contains various structures, including common carotid artery (CCA), cervical internal carotid artery (ICA), vagus nerve, cervical sympathetic chain, internal jugular vein, lymph nodes, and congenital remnant of second branchial cleft. Masses arising from these structures have characteristic radiological appearances and displacement patterns of surrounding structures.

\section{Case 1}

A 27-year-old female presented with painless swelling on the left side of the neck. An MR examination showed a large, well-defined, oval-shaped mass lesion on the left side of the neck, in the carotid space (Fig. 1). There was homogenous enhancement on delayed postcontrast study. No enhancement was seen in the arterial phase. Sagittal images of the lesion showed a tail-like extension on superior and inferior aspects (Fig. 2). The proximal external and internal carotid arteries were displaced anteromedially, while the internal jugular vein was displaced posteriorly (Fig. 1).

\section{Consultant}

Department of Magnetic Resonance Imaging, Lilavati Hospital and Research Centre, Mumbai, Maharashtra, India

Corresponding Author: Makarand Kulkarni, Consultant Department of Magnetic Resonance Imaging, Lilavati Hospital and Research Centre, Mumbai, Maharashtra, India, e-mail: makarand_kul@yahoo.com

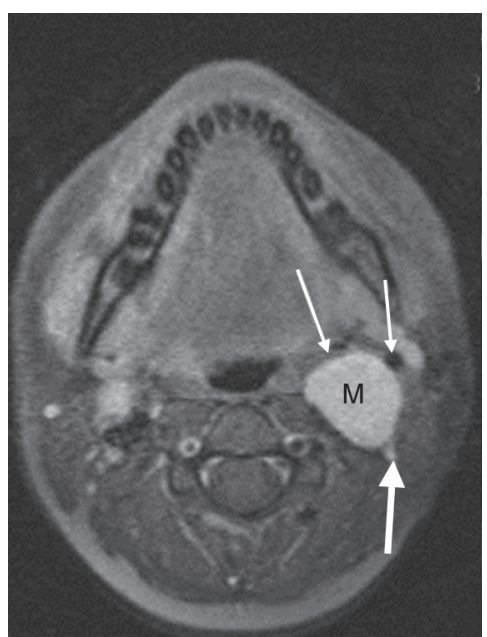

Fig. 1: Contrast-enhanced T1 image of the neck in the axial plane showing a mass lesion (M) in the left carotid space displacing the internal and external carotid arteries anteriorly and jugular vein compressed and displaced posteriorly

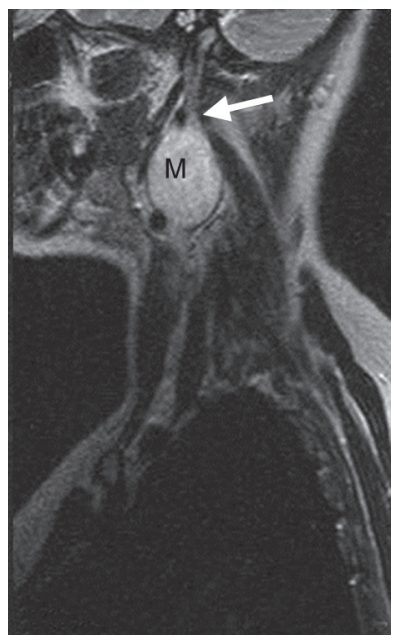

Fig. 2: Sagittal section of the neck showing an oval mass with a tail-like superior extension (vagal schwannoma)

\section{Case 2}

A 54-year-old female presented with pain and swelling on the right side of the neck. There was a bruit on palpation and auscultation. A magnetic resonance imaging (MRI) showed a mass lesion in the right side of the neck at the level of carotid bifurcation, splaying the internal and external carotid arteries (Fig. 3). It showed intense bright signals on T2-weighted images with flow voids within the tumor (Fig. 4). On contrast-enhanced MR angiogram, there was intense enhancement on arterial phase (Fig. 5). 


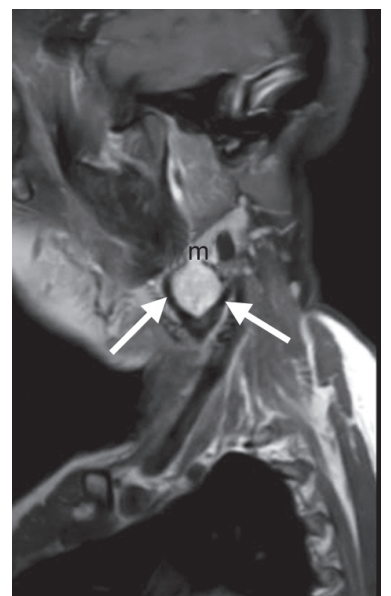

Fig. 3: Sagittal T2 section of neck showing a mass $(\mathrm{m})$ at carotid bifurcation, splaying external and internal carotid arteries (arrows)

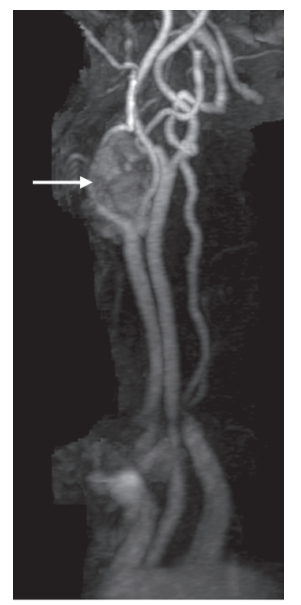

Fig. 5: Contrast-enhanced magnetic resonance angiogram showing enhancing mass (arrow) at carotid bifurcation

\section{DISCUSSION}

The differential diagnosis of carotid space masses include vagal schwannoma, carotid body tumor, cervical sympathetic chain mass, glomus vagal tumor, enlarged lymph nodes, and second branchial cleft cyst. Imaging differential between vagal schwannoma and paraganglioma is important as biopsy of highly vascular paragangliomas is not recommended. ${ }^{1}$

\section{Vagal Schwannoma}

Vagal schwannomas are the tumors that occur in the middle age between 30 and 50 years with no sex predisposition. They are usually asymptomatic but may produce hoarseness of voice or paroxysmal cough on palpation. This is a unique sign of vagal schwannoma. ${ }^{1-3}$ The vagus nerve runs in carotid sheath between ICA or CCA and internal jugular vein (IJV). ${ }^{2}$ Therefore, vagal schwannoma displaces ICA/CCA anteriorly and IJV posteriorly as seen in case $2 .^{1,4}$ Typically, vagal schwannoma exhibits a tail-like extension on its superior and inferior aspects, suggestive of entering and exiting

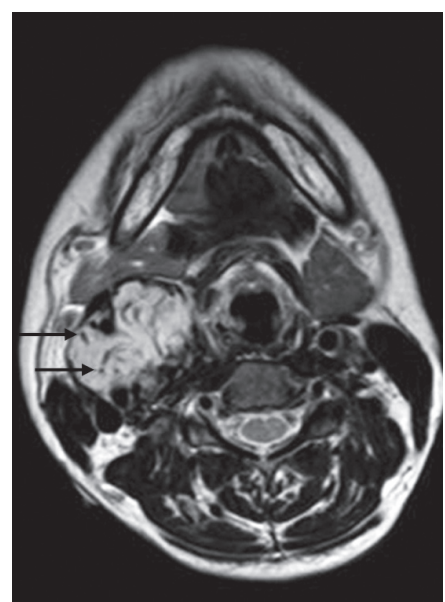

Fig. 4: T2-weighted axial image of the neck showing a mass lesion $(\mathrm{m})$ with flow voids within (small black arrows)

nerve, which is highly suggestive of neurogenic tumor. ${ }^{2}$ These findings are well illustrated in case 1. Vagal schwannomas are usually hypovascular ${ }^{2,3}$ and do not enhance on early phase of contrast. But they retain the contrast on delayed postcontrast due to the obstruction of venous drainage. Surgical excision is the treatment of choice for vagal schwannoma.

\section{Carotid Body Tumor}

They are the most common cervical paragangliomas arising at the carotid bifurcation and are highly vascular tumors. ${ }^{1}$ They cause characteristic splaying of external and internal carotid arteries. On T2-weighted images, they show characteristic flow voids described as salt and pepper appearance, suggestive of high vascularity of the tumors. ${ }^{1,2}$ This feature is best demonstrated in case 2 . Ascending pharyngeal artery is a typical feeding artery for these tumors. ${ }^{1}$ Surgical excision is the treatment of choice with preoperative embolization in larger lesions. ${ }^{1}$

\section{CONCLUSION}

Depending on the contents of carotid space, the mass lesions arising from the carotid space can be differentiated depending on their morphology and displacement pattern. The above two cases give classical pictures of vagal schwannoma and carotid body tumor.

\section{REFERENCES}

1. Ibeh C, Potigalio V. Enhancing carotid space mass. J Am Osteopath Coll Radiol 2015;4(3):24-26.

2. Anil G, Tan T-Y. CT and MRI evaluation of nerve sheath tumor of cervical vagus nerve. AJR Am J Roentgenol 2011 July;197(1):195-201.

3. Chiophalo MG, Longo F, Maronae U, Franco R, Petrillo A, Pizzullo L. Cervical vagal schwannoma. A case report. ACTA Otorhinolaryngol Ital 2009 Feb;29(1):33-35.

4. Anil G, Tan TY. Imaging characteristic of schwannoma of cervical sympathetic chain. A review of 12 cases. Am J Neuroradiol 2010 Sep;31(8):1408-1412. 